\title{
Correction to: Students' perception and acceptance of web-based technologies: a multi-group PLS analysis in Romania and Spain
}

\author{
Nuri Balta ${ }^{1}$ • Liliana Mâță ${ }^{2}$ • Carlos Hervás Gómez ${ }^{3}$ • Katerina Tzafilkou ${ }^{4}$ \\ Published online: 21 May 2020 \\ (C) Springer Science+Business Media, LLC, part of Springer Nature 2020
}

\section{Correction to: Education and Information Technologies https://doi.org/10.1007/s10639-020-10170-y}

The original version of this article unfortunately contained formatting errors in the title and author names.

The title is changed from "Students' perception and acceptance of web-based technologies: a multi-group pls analysis in romania and spain" to "Students' perception and acceptance of web-based technologies: a multi-group PLS analysis in Romania and Spain".

The online version of the original article can be found at https://doi.org/10.1007/s10639-020-10170-y

\section{Katerina Tzafilkou}

katerinatzaf@gmail.com

Nuri Balta

baltanuri@gmail.com

Liliana Mâță

lsacara@yahoo.com; liliana.mata@ub.ro

Carlos Hervás Gómez

carloshervas@gmail.com

1 Suleyman Demirel University, Abylai khan street, 1/1, Kaskelen, Kazakhstan

2 Vasile Alecsandri University of Bacău, Mărășești Street, 157, 600115 Bacău, Romania

3 University of Seville, 4 San Fernando Str. Sevilla, 41004 Sevilla, Spain

4 University of Macedonia, Greece, Egnatia 156, 54636 Thessaloniki, Greece 
The format of the author names is changed from "Balta Nuri, Mâță Liliana, Hervás Gómez Carlos, Tzafilkou Katerina" to "Nuri Balta, Liliana Mâţă, Carlos Hervás Gómez, Katerina Tzafilkou".

The original article has been corrected.

Publisher's note Springer Nature remains neutral with regard to jurisdictional claims in published maps and institutional affiliations. 